\title{
AS IMPLICAÇÕES DO CONCEITO DE PATRIMÔNIO VIVENCIAL COMO UMA ALTERNATIVA PARA A EDUCAÇÃO MULTILÍNGUE
}

\author{
Implications of the concept of funds of perejivanie as an alternative for \\ multilingual education
}

Antonieta Heyden MEGALE Instituto Singularidades antonietaheyden@hotmail.com http://orcid.org/0000-0003-2742-4551

Fernanda Coelho LIBERALI Pontifícia Universidade Católica - PUC/SP liberali@uol.com.br http://orcid.org/0000-0001-7165-646X

RESUMO: Este artigo tem como objetivo construir e sugerir o conceito de patrimônio vivencial como uma proposta de congregação da noção de patrimônios de conhecimento (HOGG, 2011; MOLL et al., 1992) ao conceito de perejivanie/vivência (VYGOTSKY, 1994; VYGOTSKY, 2010), de repertório (BUSCH, 2012; 2015; BLOMMAERT, 2013; BLOMMAERT; BACKUS, 2013; OTSUJI; PENNYCOOK, 2010; RYMES, 2014; GARCÍA; WEI, 2014) e de translinguagem (GARCÍA, 2009; CANAGARAJAH, 2011; ROCHA; MACIEL, 2015). Essa proposição focaliza a necessidade de considerar o contexto de superdiversidade (VERTOVEC, 2007) em que vivemos e as demandas que ele nos impõe neste momento histórico. Consideramos que não seja mais possível pensar em contextos educacionais encastelados na reprodução de saberes fixos, de um determinado grupo social imposto a outro. Em uma proposta de globalização como possibilidade (SANTOS, 2003), consideramos central que os espaços de aprendizagens sejam constituídos para a criação de possibilidades de ser, agir, sentir, viver o mundo. Nessa direção, a educação multilíngue precisa considerar a construção de possibilidades de/para o futuro.

PALAVRAS-CHAVE: Patrimônio vivencial; Patrimônios de conhecimento; Perejivanie; Repertório; Translinguagem; Multilíngue.

\begin{abstract}
This article aims to construct and suggest the concept of funds of perejivanie as a proposal to bring together the notion of funds of knowledge (HOGG, 2011; MOLL et al., 1992) to the concept of perejivanie (VYGOTSKY, 1994; VYGOTSKY, 2010), repertoire (BUSCH, 2012; 2015; BLOMMAERT, 2013; BLOMMAERT;
\end{abstract}


BACKUS, 2013; OTSUJI; PENNYCOOK，2010; RYMES，2014; GARCÍA; WEI, 2014) and translanguaging (GARCÍA, 2009; CANAGARAJAH, 2011; ROCHA; MACIEL, 2015). This proposition focuses on the need to consider the context of superdiversity (VERTOVEC, 2007) in which we live and the demands that it imposes on us at this historical moment. We consider that it is no longer possible to think of educational contexts entrenched in the reproduction of fixed knowledge, from one particular social group imposed to another. In a proposal of globalization as a possibility (SANTOS, 2003), we consider it central that learning spaces are constituted for the creation of possibilities of being, acting, feeling, living the world. In this sense, the multilingual education needs to consider building possibilities of / for the future.

KEYWORDS: Funds of perejivanie; Funds of knowledge; Perejivanie; Repertoire; Translanguaging; Multilingual.

\section{INTRODUÇÃO}

Com o objetivo de superar uma visão que coloca nos saberes historicamente acumulados pela ideologia vigente o único valor efetivamente necessário para o trabalho do educador, esta proposta pretende mostrar como o patrimônio vivencial pode se tornar um importante conceito para a organização das práticas escolares em um contexto multicultural e multilíngue. Nesse sentido, o conceito de patrimônio vivencial, ancorado nas noções de patrimônios de conhecimento (HOGG, 2011; MOLL et al., 1992), nos conceitos de perejivanie/vivência (VYGOTSKY, 1994; VYGOTSKY, 2010), de repertório (BUSCH, 2012; 2015; BLOMMAERT, 2013; BLOMMAERT; BACKUS, 2013; OTSUJI; PENNYCOOK, 2010; RYMES, 2014; GARCÍA; WEI, 2014) e de translinguagem (GARCÍA, 2009; CANAGARAJAH, 2011; ROCHA, 2015), se materializa como central ao espaço educativo em contextos multilíngues.

Esses contextos demandam não olhar para a formação dos educandos como algo pronto e acabado, que transforma as práticas de acordo com a "moda pedagógica" vigente. Ao contrário, pressupõe pensar o espaço formativo, como exigindo a compreensão e a problematização dos sujeitos com os quais interagem e de si mesmo como agentes em transformação. Envolve, assim, uma preocupação com a complexa constituição dos sujeitos na criação de possibilidades de vir a ser consubstanciadas em experiências marcantes, ricas em saberes e modos de ser, pensar, agir, sentir e viver, atravessados pela multimodalidade e multiculturalismo que constituem suas formas de participação na vida. 
Para realizar essa discussão, este artigo está organizado em cinco seções. Na primeira, é apresentado o conceito de patrimônio de conhecimentos. Na segunda, é explicado o conceito de perejivanie/vivência que expande a ideia de patrimônio e a entrelaça à de identidade. Na terceira seção, o conceito de repertório e de translinguagem é exposto na busca por expandir e situar as bases multimodais e multiculturais para o conceito de patrimônio vivencial, abordado na quarta seção. Por fim, são apresentadas considerações sobre as implicações desse conceito ao se pensar os processos pedagógicos em contextos multilíngues, por meio da exemplificação de uma prática pedagógica,

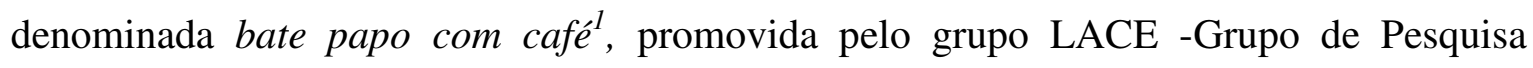
Linguagem e Atividade em Contexto Escolar - da PUC/SP.

\section{PARTINDO DO CONCEITO DE PATRIMÔNIO DE CONHECIMENTO}

O conceito de patrimônio de conhecimento surge da tradução de funds of knowledge (HOGG, 2011), com o advento de pesquisas sobre "escolas culturalmente desprovidas"2 (RYAN,1972, p. 61) e sobre "a cultura de pobreza"”3 (LEWIS, 1966, p. 19). Esses tipos de pesquisa pretendiam não apenas se contrapor a concepção de um déficit de conhecimento. Seu principal foco era pensar as práticas dos professores face às diferenças de experiências trazidas pelas crianças para a escola.

O conceito, segundo Hogg (2011), tem origem na antropologia e foi originalmente cunhado por Wolf (1966, apud HOGG, 2011) para definir "recursos e conhecimento que as famílias manipulam para sobreviver na economia doméstica"4 (HOGG, 2011, p. 667). Gonzalez (2005) aponta que as práticas cotidianas das famílias seriam, então, centrais para que os professores criassem bases para pensar suas práticas didáticas. A famosa pesquisa de Heath (1983), assim, tornou-se base para estudos que focalizavam a importância de o professor conhecer as práticas culturais de seus alunos na busca por organizar suas práticas didáticas.

\footnotetext{
${ }^{1}$ O bate-papo com café foi inspirado pelo Multilingual Conversation Café, realizados pela Graduate School of Education da Rutgers University (EUA).

2 No original: "culturally deprived schools" (RYAN,1972, p. 61, todas as traduções são das autoras).

${ }^{3}$ No original: "the culture of poverty" (LEWIS, 1966, p. 19).

${ }^{4}$ No original: "knowledge that households manipulate to make ends meet in the household economy" (HOGG, 2011, p. 667).
} 
De acordo com Hedges et al. (2011), consistente com perspectivas vygotskianas, o conceito de patrimônio de conhecimento apresenta uma proposta que valoriza a diversidade de conhecimentos e experiências vividas pelos aprendizes em suas famílias e contextos culturais diversos. Esse conceito assumiu uma importância grande a partir dos estudos realizados pelo grupo de Tucson que, segundo Hogg (2011), reunia pesquisadores das áreas de antropologia e educação com sede em Tucson, Arizona, EUA, na Universidade do Arizona. Esse grupo, que inclui pesquisadores como Luis Moll, Norma Gonzalez, James Greenberg e Carlos Velez-Ibane, reconheceu e propagou a profunda relevância do conceito e sua importância nos ambientes escolares a partir de inúmeros projetos de pesquisa.

Um patrimônio de conhecimento, conforme Moll et al. (1992, p. 134), poderia ser compreendido como "corpos de conhecimento e habilidades historicamente acumulados e culturalmente desenvolvidos, essenciais para o funcionamento e o bem-estar da família ou do indivíduo"5. Esses pesquisadores explicam que o conceito pode se referir a um conjunto de saberes que incluem informações, formas de pensar, de aprender e de agir em geral.

Esse conceito parece, portanto, ter sido central em colocar os pesquisadores e os educadores frente a frente com o fato de que são, por vezes, ignorantes e até arrogantes em relação aos saberes de seus alunos (PATTERSON; BALDWIN, 2001), construídos em suas experiências vividas (ANDREWS; YEE, 2006). Os patrimônios de conhecimento são o resultado das vivências das pessoas, com ênfase nas interações sociais em atividades variadas, inclusive focalizando a linguagem (MOLL; CAMMAROTA, 2010).

Conforme adverte Hogg (2011), para que seja possível uma perspectiva de trabalho efetivo com os aprendizes nessa linha, é preciso conhecer suas diversidades étnicas, principalmente, em um mundo superdiverso como explica Vertovec (2007) ${ }^{6}$. Nessa direção, como expõe Gonzalez (2005), os alunos usam seus conhecimentos construídos

\footnotetext{
${ }^{5}$ No original: "historically accumulated and culturally developed bodies of knowledge and skills essential for household or individual functioning and wellbeing" (MOLL et. al., 1992, p. 134).

${ }^{6} \mathrm{O}$ termo superdiversidade foi cunhado por Vertovec (2007), que contribuiu para o debate crítico em torno do multiculturalismo e foi imprescindível para a superação das limitações associadas à utilização da etnicidade como principal fator explicativo da diversidade. O autor, ao invocar a superdiversidade, tem como objetivo enfatizar o fato de que houve um crescimento enorme nas categorias de imigração. Isso ocorreu não apenas em termos de nacionalidade, etnicidade, língua e religião, mas deu-se, também, em decorrência das diferentes razões para a imigração e dos diferentes padrões e itinerários dos contingentes migratórios.
} 
historicamente, se apropriando de sistemas culturais múltiplos e expandindo suas possibilidades.

Os estudos de Hedges et al. (2011) sobre crianças pequenas também sugerem que os patrimônios de conhecimento podem ser constituídos e recuperados de diferentes formas. Nesses estudos, as famílias seriam importante fonte definidora de seus interesses e questionamentos. Além disso, acrescentam que a participação de crianças em eventos sociais e culturais diversos expande as experiências e, portanto, seu patrimônio de conhecimento. Finalmente, advogam que um ambiente internacionalmente rico entre aprendizes e professores pode prover oportunidades e interesses para que esse patrimônio seja acessado, reconhecido e explorado. O comprometimento dos educadores com essa gama tão variada de experiências das crianças fornece uma maneira de reconhecer e de responder, de forma mais adequada e crítica, aos interesses e questionamentos das crianças e dos educadores.

Contudo, a educação no século 21 parece ter demandas que vão além da formação de aprendizes para a criação de conhecimentos, como apontam Poole e Huang (2018). É preciso considerar, também, a constituição de identidades ou de experiências de vida relevantes a partir da noção de perezhivania, que será abordada na próxima seção.

\section{AMPLIANDO O PATRIMÔNIO A PARTIR DAS PEREZHIVANIA/VIVÊNCIA}

O conceito de perejivanie é usualmente traduzido como experiência emocional (emotional experience), experiência vivida (lived experience) ou apenas experiência (experience) no inglês (BLUNDEN, 2014). Em algumas traduções do português (VINHA; WELCMAN, 2010), aparece também como vivência, expressão que escolhemos para uso neste texto. A composição do termo em russo, segundo Delari e Bobrova Passos (2009), inclui o prefixo "pere" que indica a ideia de "através" e "zhivat" significa "viver". Assim, como sugerem Vinha e Welcman (2010), traduzindo Vygotsky, o conceito perejivanie envolve a vida em transformação, ou vivência, terminologia, aqui, adotada como tradução.

González Rey (2016) explica que o conceito oferece uma nova perspectiva para a compreensão do sistema psicológico humano, porque valoriza e inclui, também, a emoção como uma de suas características essenciais. Nisso, está a inseparabilidade entre emoção e 
cognição expostas por Vygotsky (1999) em "Sobre a questão da psicologia do ator "”.

Segundo o autor (VYGOTSKY, 1994), a vivência está ligada a forma como cada sujeito experiencia uma mesma situação e como é por ela afetado. Para Vygotsky, a vivência seria o prisma a refratar fatores externos de modos particulares. O autor explica que cada sujeito experimenta momentos de forte tensão e contradição, vividos com outros, de formas particulares que vem a constituir seus modos especiais de internalizar a realidade.

Para Vygotsky (VINHA; WELCMAN, 2010), fatores externos não determinam o desenvolvimento futuro do sujeito, mas são interpretados pelos sujeitos e,de forma interdependente, passam a influenciar as futuras formas de ser, agir e sentir de cada um. Nessa linha, segundo Van der Veer e Valsiner (1994, p. 354), o conceito de vivência permite entender que "uma e a mesma situação objetiva pode ser interpretada, percebida, experimentada ou vivenciada por diferentes crianças de diferentes maneiras" ${ }^{8}$.

Essas vivências podem ocorrer a partir de eventos dramáticos vividos com o outro. Como aponta Clarà (2016, p. 285), estariam relacionadas a "experienciando-como-luta", ao pressupor que as pessoas atravessem uma situação crítica em busca por equilíbrio psicológico. Blunden (2016), na mesma direção, explica que o verbo perezhivat refere-se à sobre-viver (sur-vive). Portanto, envolveria viver até que não haja mais dor ou mesmo, sobreviver a dor, indicando superar um obstáculo. Explica, ainda, que a ideia estaria relacionada a viver algo, sem esquecer o que ocorreu, até que possa ter sobrevivido a isso $^{10}$ (BLUNDEN, 2016, p. 3).

Similarmente, segundo Liberali e Fuga (2018), é possível compreender o processo de transformação do sujeito de forma coletivizada, colaborativa e dinâmica, considerando que seu desenvolvimento decorre dessas experiências dramáticas vividas em sociedade e da forma como elas são refratadas por cada um deles a partir de suas histórias invocadas.

Somando-se a isso, Esteban-Guitart e Moll (2014, p. 33) explicam que "as experiências vividas são o resultado de uma interação entre as pessoas e o mundo e têm

\footnotetext{
${ }_{8}^{7}$ On the question of the Psychology of the Creative Actor

${ }^{8}$ No original: "servesto express the idea that one and the same objective situation may be interpreted, perceived, experienced or lived through by different children in different ways" (VAN DER VEER; VALSINER, 1994, p. 354).

${ }^{9}$ No original: "experiencing-as-struggle” (CLARÀ, 2016, p. 285).
} 
uma importância subjetiva singular em cada pessoa"11. Ademais,os autores enfatizam que as vivências são o lado subjetivo da cultura, construído a partir da combinação das experiências que os sujeitos carregam para a situação a partir de suas vivências anteriores, com as potencialidades e restrições providas pelo contexto. Esses autores reiteram a importância da conjugação entre o modo como cada sujeito experiencia a situação e o efeito que cada situação tem sobre ele.

Nessa direção, os pesquisadores apontam que é possível dizer que as vivências sejam culturalmente organizadas, já que é por meio delas que os sujeitos "internalizam, incorporam e originam no mundo social, guiados por processos culturais"12 (ESTEBANGUITART; MOLL, 2014, p. 34). Esse processo é realizado com a presença de fatores histórico-culturais concretos (instituições, artefatos, práticas culturais, relações sociais, geografias, crenças) por meio da participação efetiva dos sujeitos em atividades humanas.

Em um enquadre que conecta os patrimônios de conhecimento a questões de identidade, os autores apontam que as identidades são criadas e recriadas nas interações entre as pessoas em um determinado contexto e passam a ser experiências vividas em si. Na mesma linha, elucidam que essa relação entre a identidade e as vivências permite uma compreensão da identidade incorporada a processos sociais, históricos e culturais. Assim, esclarecem que o patrimônio de conhecimento pode ser visto como repertórios que os sujeitos acessam na constituição de suas identidades.

Portanto, torna-se possível falar em patrimônios de identidade como o conjunto de recursos ou "caixa de ferramentas e signos", "historicamente acumulados, culturalmente desenvolvidos e distribuídos socialmente, essenciais para a autodefinição, a autoexpressão e a autocompreensão das pessoas"13 (ESTEBAN-GUITART; MOLL, 2014, p. 37). Considerando os recursos que constituem a identidade dos sujeitos, os autores propõem cinco tipos de patrimônio de identidades: geográfico (por exemplo,

\footnotetext{
${ }^{10}$ No original: "[...] lives your pain, not letting you forget what has happened, and you keep living through it over and over again, working-through it, repeating it until you have passed through it, and have survived" (BLUNDEN, 2016, p. 3)

${ }^{11}$ Lived experience is the result of any transaction between people and the world, emphasizing the subjective significance of the situation on the person (ESTEBAN-GUITART; MOLL, 2014, p. 33).

12 No original: "internalize, incarnate, and originate in a social context guided by cultural processes" (ESTEBAN-GUITART; MOLL, 2014, p. 34).

${ }^{13}$ No original: "[...] funds of identity are historically accumulated, culturally developed, and socially distributed resources that are essential for people's self-definition, self- expression, and selfunderstanding. In other words, the term funds of identity which we are using here denotes a set of resources or box of tools and signs" (ESTEBAN-GUITART; MOLL, 2014, p. 37).
} 
um determinado modo de vestir como marca de um local), prático (atividades profissionais, domésticas), cultural (categorias social como idade, gênero, grupo étnico), social (parentes, amigos, colegas) e institucional (família, casamento, igreja).

Para Esteban-Guitart e Moll (2014), para além dos conhecimentos, os patrimônios de identidade seriam,então,construídos e apropriados pelos sujeitos no processo de construção de suas próprias identidades. Estariam ligados às experiências vividas por eles, que seriam mobilizadas tanto por estudantes como professores para mediar suas construções identitárias e práticas pedagógicas (ESTEBAN-GUITART, 2016). Os patrimônios de conhecimento se tornam patrimônios de identidade "quando as pessoas internalizam ativamente os recursos da família e da comunidade para criar significado e se descreverem" ${ }^{14}$ (ESTEBAN-GUITART, 2016, p. 33). Nessa direção, envolveria a presença dessas marcas identitárias como parte do processo pedagógico, criando laços com as estratégias de ensino-aprendizagem de novas potencialidades.

Poole e Huang (2018) também chamam atenção para o fato de que é preciso considerar que os aprendizes se apropriam de suas culturas de forma contextualizada e temporariamente situada, e que, por conta disso, conceitos como patrimônios de conhecimento e de identidade se tornam conceitos centrais. Os autores (2018) explicam, assim como Esteban-Guitart e Moll (2014), que os patrimônios de identidade estão explicitamente ligados à forma de experiências vividas e, portanto, ao conceito vygoskiano de perejivanie (1994).

Pautados em autores que vem recentemente discutindo o conceito de perejivanie (BLUNDEN, 2014, 2016; CLARÀ, 2016; GONZÁLEZ REY, 2016), Poole e Huang (2018, p. 126) chamam de patrimônios existenciais de identidade as "experiências positivas e negativas que os estudantes desenvolvem e apropriam para se definirem e para ajudá-los a crescer como seres humanos" ${ }^{, 15}$.

Poole e Huang (2018) explicam que enquanto Clarà (2016) reforça o caráter traumático, conflituoso, dramático das vivências, Blunden (2016) focaliza o episódio crítico (experiência traumática ou de mudança de vida), a reflexão (processo de refletir e

\footnotetext{
${ }^{14}$ No original: "[...] when people actively internalize family and community resources to make meaning and to describe themselves" (ESTEBAN-GUITART, 2016, p. 33).

${ }^{15}$ No original: "positive and negative experiences that students develop and appropriate in order to define themselves and to help them grow as human beings" (POOLE; HUANG, 2018, p. 126).
} 
conscientizar-se sobre a experiência vivida) e a catarse (processamento ou assimilação de um episódio crítico). Semelhantemente, González Rey (2016) aponta o caráter importante das experiências positivas e negativas que sustentam os processos subjetivos humanos se integrando e se desdobrando de formas únicas para cada um. Essas ideias ajudam a colocar destaque na situação crítica como central para o trabalho de professores porque, como apontam Poole e Huang (2018), é a situação crítica (ou evento dramático, como sugeria Vygotsky) que cria oportunidades de expansão do sujeito em desenvolvimento.

$\mathrm{Na}$ seção seguinte, discorreremos acerca dos conceitos de repertório e translinguagem, o que servirá de base para a conceituação do conceito de patrimônio vivencial, objetivo deste artigo, e para a distinção entre esse conceito e o de patrimônio de identidade.

\section{DIALOGANDO COM OS CONCEITOS DE REPERTÓRIO E TRANSLINGUAGEM}

Vários especialistas, tais como Busch (2012, 2015), Blommaert (2006), Blommaert e Backus (2012), Blommaert e De Fina (2015), Rymes (2014) e Otsuji e Pennycook (2010), entre outros, vêm, mais recentemente, enfatizando o fato de que as pesquisas da área de multilinguismo devem focalizar os recursos mobilizados pelo sujeito para interagir com o mundo, e não apenas as línguas que utiliza para interação de modo compartimentalizado. Essa mudança na forma pela qual o sujeito bi/multilíngue é entendido pode ser justificada devido ao fato de que não podemos conceber o indivíduo multi/bilíngue como um duplo monolíngue que acessa saberes relacionados a apenas uma de suas línguas a partir das demandas do contexto, enquanto os saberes relacionados a(s) sua(s) outra(s) língua(s) ficariam desativados. Já é sabido que o sujeito bilíngue possui um único sistema linguístico com características que pertencem às diferentes línguas que constituem seu repertório. Além disso, os saberes construídos por meio de uma de suas línguas integram seu repertório e o sujeito, assim, transfere conhecimentos de uma língua para outra.

Nesse sentido, Busch (2012) defende a noção de repertório linguístico em detrimento das divisões clássicas de primeira e segunda língua. O conceito de repertório linguístico está associado aos trabalhos de Gumperz (1960; 1964) em duas cidades rurais 
de tamanho mediano, por ele, denominadas como comunidades de fala ${ }^{16}$. Essas comunidades são concebidas pelo autor como grupos humanos que mantém interações frequentes por meio de um conjunto de signos verbais compartilhados, que os separam de outros grupos humanos por diferenças significativas no uso da linguagem (GUMPERZ, 1972).

Por sua vez, a noção de repertório verbal de uma comunidade de fala é definida por Gumperz (1964, p.137) como "a totalidade das formas linguísticas empregadas no curso das interações socialmente significativas" ${ }^{" 17}$ e que contém todos os modos aceitáveis de formular mensagens, por isso, fornecem "as armas para a comunicação diária"18 (p. 138). Para o autor, o indivíduo faz escolhas relacionadas ao uso de seu recurso linguístico sujeitas a restrições gramaticais e sociais e, por isso, essas escolhas são limitadas por convenções aceitáveis que servem para classificar tipos de expressão, como, por exemplo, formal, técnica, literária e humorística, entre outras.

Busch (2012) propõe a redefinição do conceito de repertório verbal a partir do fato de que as comunidades de fala tornaram-se temporárias devido às condições da superdiversidade (VERTOVEC, 2007) e, com isso, estão cada vez mais sujeitas a rápidas mudanças, uma vez que reúnem indivíduos com diferentes repertórios, recursos e práticas comunicativas.

A autora (BUSCH, 2012, 2015) salienta que, para se posicionar para além do conceito de comunidade de fala, deve-se assumir uma perspectiva biográfica que vincule o repertório linguístico do sujeito à sua trajetória de vida. Outra possibilidade seria assumir uma perspectiva espacial, como proposta por Otsuji e Pennycook (2010), ao cunharem o termo "repertório espacial", que é a relação do repertório formado pela trajetória de vida do sujeito com os recursos linguísticos disponíveis em um local específico.

Em consonância ao proposto pelos autores, Blommaert e Backus (2012) entendem o repertório linguístico como uma miscelânea de recursos, habilidades e competências aprendidas por um indivíduo que, por ser móvel, ao longo de sua trajetória de vida, depara-se com situações de aprendizado de língua formais e encontros informais com a

\footnotetext{
${ }^{16}$ É preciso apontar que o conceito de "comunidade de fala" vem sendo alvo de críticas, nos últimos anos, por pressupor a existência de uma homogeneidade no interior do grupo social que a comporia. A esse respeito, ver, por exemplo, Martin-Jones; Blackledge e Creese (2012, p. 4).

17 No original: "The totality of linguistic forms regularly employed in the course of socially significant interaction" (GUMPERZ, 1964, p. 137).

${ }^{18}$ No original: "the weapons of everyday communication" (GUMPERZ, 1964, p. 138).
} 
língua. Os autores defendem a ideia de que o repertório linguístico reflete a vida do sujeito, que ocorre em um espaço real sociocultural, histórico e político e que não remete apenas ao seu local de nascimento.

Rymes (2014), por sua vez, defende a ideia de que um repertório comunicativo não é formado apenas pela língua, mas, de igual modo, por elementos não linguísticos ${ }^{19}$, como a forma do sujeito se vestir, a cor de sua pele, o comprimento de seu cabelo, o modo de se sentar durante uma entrevista ou o tipo de mala na qual carrega papéis. Segundo a autora, todos esses aspectos podem ter um efeito em como os encontros com a diversidade se revelam e, por isso, fazem parte do repertório comunicativo do sujeito.

Busch $(2015$, p. 7) propõe que "o conceito de repertório linguístico precisa ser expandido de modo a incluir pelo menos duas outras dimensões: as ideologias linguísticas e o que a autora denomina a experiência vivida da língua" ${ }^{20}$. No tocante às ideologias linguísticas, a autora explica que atitudes pessoais em relação à língua são amplamente determinadas pelo valor atribuído a ela ou a uma variedade dela em um espaço social. No caso de repertórios linguísticos, essa ideia está associada ao poder restritivo ou de exclusão das categorizações linguísticas, como, por exemplo, quando falantes de uma língua ou de um modo de falar específico não são reconhecidos ou não se percebem como falantes legítimos dessa língua.

O conceito de experiência vivida da língua proposto por Busch tem base na fenomenologia da percepção, desenvolvida, na década de 1940, por Merleau-Ponty. Para o autor, segundo Busch (2015), a língua é um fenômeno essencialmente corpóreo, uma vez que, assim como o gesto e a emoção, ela "é primeiramente, e acima de tudo, um posicionamento do sujeito em relação ao mundo" ${ }^{21}$ - e é apenas então que a língua se torna "um ato cognitivo de representação e simbolização" (p. 10) ${ }^{22}$. Desse modo, a autora reivindica que, ao conceber a língua como parte dessa memória corpórea, é possível entender o repertório, em sua dimensão biográfica, "como uma estrutura que carrega

\footnotetext{
19 A proposta de Rymes (2014) está relacionada à relevância dos estudos contemporâneos sobre multimodalidade. Jewitt (2009), citada por Liberali et al. (2015, p. 6), aponta para o fato de que "a multimodalidade ressalta a importância da compreensão e análise do repertório de significados formados pelos recursos socialmente moldados ao longo do tempo e culturalmente compartilhados por determinada comunidade".

${ }^{20}$ No original: "the concept of repertoire needs to be expanded to include at least two further dimensions: that of linguistic ideologies, and that of lived experience of language." (BUSCH, 2015, p. 7).

${ }^{21}$ No original: "language is first and foremost about positioning oneself in relationship to the world" (BUSCH, 2015, p. 10).
} 
traços de experiências passadas de interações situadas e de práticas linguísticas cotidianas derivadas dessas experiências" (p. 11) ${ }^{23}$.

Nesse sentido, Blommaerte Backus (2012) explicam que os repertórios podem ser considerados "registros de mobilidade" ${ }^{24}$, que incluem movimento de pessoas, recursos linguísticos ou mesmo disputas sociais. Desse modo, os repertórios parecem nos permitir documentar as trajetórias percorridas pelos sujeitos: as oportunidades, os limites, as desigualdades que vivenciaram, os ambientes de aprendizagem que tiveram (ou não) acesso, seus movimentos através do espaço físico e social e seu potencial de agência em disputas sociais específicas. Para além do proposto pelos autores, acreditamos também que os repertórios podem delinear e definir o potencial de mobilidade (futura) do sujeito.

Frente a essa noção de repertório linguístico, Busch (2012), com base em pesquisas anteriores realizadas por García (2009), considera necessário reexaminar esse conceito a partir da noção de translinguagem ${ }^{25}$.

A esse respeito, García (2009) defende que é coerente a denominação translinguagem quando nos referimos às práticas linguísticas do sujeito multilíngue a partir da perspectiva dos usuários, e não apenas descrevemos o uso das línguas ou o contato linguístico a partir da própria língua. Para essa autora (2009), translinguagem se relaciona às múltiplas práticas discursivas nas quais sujeitos multilíngues se engajam para que seu mundo faça sentido. Dessa forma, a autora enfatiza que a translinguagem vai além da prática de "alternância de código" e "do uso híbrido das línguas", embora eles façam parte desse fenômeno.

De acordo com a autora, sujeitos multilíngues translinguam não apenas para incluir outros indivíduos em suas interações e para facilitar a comunicação entre eles, mas também para promover entendimento e compreensão mais profundos e, dessa maneira, significarem seu mundo.

Como essa noção tem recebido cada vez mais atenção dos estudiosos em áreas diversas, Canagarajah (2011) fez um levantamento dos diferentes nomes que o fenômeno recebe em áreas distintas, como, por exemplo, codemeshing, translingual writing,

\footnotetext{
${ }^{22}$ No original: "a cognitive act of representation and symbolization" (BUSCH, 2015, p. 10).

${ }^{23}$ No original: "as a structure bearing the traces of past experience of situated interactions, and of the everyday linguistic practices derived from this experience" (BUSCH, 2015, p. 11).

${ }^{24}$ No original: "records of mobility" (BLOMMAERT; BACKUS, 2012, p. 27).

${ }^{25}$ No original: translanguaging.
} 
fluidlects e polylingual languaging. O autor explica esse conceito ao afirmar que, para um indivíduo multilíngue, suas línguas fazem parte de um repertório que é acessado para propósitos comunicativos. Segundo o autor, as línguas formam um sistema integrado e, dessa forma, a competência multilíngue emerge de práticas locais nas quais as línguas são negociadas para comunicação. Ainda, salienta que, em contexto de multilinguismo, a competência linguística dos sujeitos não consiste em competências separadas para cada uma das línguas, mas em uma multicompetência que funciona simbioticamente para as diferentes línguas no seu repertório. E, por essas razões, a competência de multilíngues tem como foco a construção do repertório, como, por exemplo, o desenvolvimento de habilidades em funções diferenciadas para cada língua, e não tem como foco o conhecimento total de cada uma das duas línguas.

A partir dessa perspectiva, García (2009) ressalta que conceitos como “semilinguismo", "língua dominante", "língua materna", "aprendizes de segunda língua” e "aprendizes de línguas de herança", até então, aceitos nos estudos sobre educação multilíngue, não são produtivos. Isso ocorre, primeiramente, porque esses conceitos emergiram a partir de estudos sobre multilinguismo realizados apenas por ângulos linguísticos, e não a partir da perspectiva dos próprios sujeitos que translinguam como uma prática comum. Além disso, a autora afirma que ao adotar a perspectiva dos sujeitos que translinguam, então, pode-se substituir termos como "aprendizes de segunda língua" e "aprendizes de línguas de herança”, simplesmente, por "indivíduos bi/multilíngues". García (2009) salienta que colocar o multilinguismo no centro da discussão e insistir que esses alunos são bilíngues emergentes, ou bilíngues engajados em práticas translíngues complexas, pode levar ao abandono de pontos de vista monolíngues e, com isso, passarse-ia a utilizar "lentes heteroglóssicas" (GARCÍA, 2009), que permitiriam uma visão mais abrangente da extensão das práticas linguísticas e das experiências de indivíduos bilíngues.

Por conseguinte, concordamos com Rocha e Maciel (2015) que reconhecem, na translinguagem, seu caráter híbrido e questionam a separação rigidamente delimitada entre linguagens, modalidades ou modos de construção de sentidos.

Entende-se, neste estudo, portanto, que o repertório linguístico não é algo que o sujeito simplesmente possui, mas que é formado e desdobrado em processos intersubjetivos localizados na fronteira entre o eu e o Outro. Com isso, o desempenho do 
sujeito é aqui compreendido como alguém que "opera em um universo discursivo próprio, que não é nem o universo discursivo do falante 'monolíngue', nem o do falante em L2" (MAHER, 2007, p. 77-78). Dessa forma, assumimos que o sujeito multilíngue funciona em um terceiro lugar e está propenso à permeabilidade das linguagens que o constituem e, com isso, sua identidade como multilíngue está sempre em construção.

Assim, entendemos que os conceitos de repertório e translinguagem unidos ao de patrimônio de conhecimento e de identidade e de perejivanie podem oferecer forte contribuição à educação multilíngue. Nossa proposta conceitual é apresentada na seção a seguir.

\section{A PROPOSIÇÃO DE CONCEITO DE PATRIMÔNIO VIVENCIAL}

O objetivo desta seção é a proposição do conceito de patrimônio vivencial como uma congregação da noção de patrimônios de conhecimento e de identidade, ao conceito de perejivanie/vivência, de repertório e de translinguagem, discutidos ao longo deste artigo.

Se, como Blommaert e Backus (2012) afirmam, toda vez que utilizamos o conceito de repertório, ele pressupõe conhecimento, uma vez que "ter um repertório particular está relacionado a saber como utilizar os recursos que ele combina" ${ }^{, 26}$, a noção de patrimônio vivencial, aqui proposta, integra a vivência e a experiência ao conhecimento, deflagrado pelos conceitos de repertório e translinguagem, corroborando a inseparabilidade entre emoção e cognição defendida por Vygotsky (1999). No entanto, o conceito de patrimônio vivencial vai além das questões que estão na base da discussão de patrimônio de identidade, uma vez que integra todo o potencial de significar e viver a realidade.

O patrimônio vivencial, como propomos, é, portanto, o conjunto de recursos acumulados a partir de eventos dramáticos vividos com o outro,que se materializam (ou não) nos "meios de falar" (BLOMMAERT; BACKUS, 2012, p. 3 ) $^{27}$. Em outras palavras, são todos os meios pelos quais os sujeitos interagem com o mundo, e compreendem e vivem aspectos linguísticos, culturais, emocionais e sociais.

O conceito de patrimônio vivencial nos possibilita, desse modo, pensar os

\footnotetext{
${ }^{26}$ No original: “'having' a particular repertoire is predicated on knowing how to use the resources that it combines" (BLOMMAERT; BACKUS, 2012, p. 3).

${ }^{27}$ No original: "means of speaking".
} 
processos de ensino-aprendizagem para além dos saberes, relacionados aos conteúdos específicos, que a escola precisa ensinar ou apenas às questões emocionais, que podem emergir no contexto educacional. Essa noção enfatiza a correlação entre toda gama de fatores apropriados pelos sujeitos - professores e alunos - ao longo de suas vidas e as propostas feitas pela escola para potencializar a mobilidade do sujeito.

Além disso, valoriza a diversidade de conhecimentos de mundo, saberes linguísticos, recursos multimodais, emoções e experiências vividas pelos aprendizes em suas famílias e contextos culturais diversos. Dessa forma, os diversos patrimônios vivenciais em contato, oriundos de contextos superdiversos, são entendidos como possibilidade de ampliação dos recursos de todos os participantes do processo educacional. É por meio da evidenciação dos patrimônios vivenciais diversos que os alunos e educadores têm a oportunidade de se deparar com diferentes narrativas compostas por formas variadas de pensar, agir, aprender, conceber e construir conhecimentos, objetos, experiências e sentimentos. Essas narrativas diversas também podem passar a compor e/ou modificar os recursos que constituem o patrimônio vivencial dos participantes do evento se provocarem a emergência de uma nova configuração do humano a partir de eventos dramáticos vividos com o outro (perejivanie).

Assim, considerando a proposta de uma nova globalização (SANTOS, 2003), com possibilidades mais humanas, é preciso que as práticas educativas se realizem para ampliar as possibilidades de conhecer, ser, sentir, pensar e agir dos sujeitos. Como abordam Liberali e Fuga (2018), é preciso que a formação constitua os sujeitos com agência, o que pressupõe possibilidades de mudanças que vão além de eventos individuais e situacionais e prevê uma relação constantemente co-construída e renegociada com os envolvidos na interação.

Para a construção de um mundo mais solidário e compartilhado, é necessário que os sujeitos em contextos educativos multilíngues percebam seu viver como múltiplo e possam experimentar essa multiplicidade como uma forma de ir além de si mesmos e encontrar os vários Outros com os quais poderão ter condições de conviver. Para isso, há de se apostar na construção intencional de novos recursos que combinados, mobilizados e materializados a partir das demandas do contexto podem possibilitar a interação com o mundo e, com isso, a emergência de novos eventos dramáticos, que sempre pressupõem a interação com o outro, a fim de gerar desenvolvimento. 
Desse modo, o espaço educativo precisa ser pensado como muito mais amplo do que um simples espaço de construção de saberes. É preciso que ofereça experiências marcantes em que repertórios amplos de vida possam, realmente, ser considerados patrimônios vivenciais a serem carregados e recuperados em novas, imprevisíveis e incontroláveis experiências.

Nessa direção, propusemos em março de 2019, uma atividade educativa, que nomeamos como Bate-papo com Café, inspirados na experiência do Multilingual Conversation Café, realizados pela Graduate School of Education da Rutgers University (EUA). Nele, aprendizes de português ${ }^{28}$, de diversas nacionalidades - bolivianos, sírios e haitianos - com línguas distintas e conhecimentos variados português, foram reunidos junto a professores e professoras no Pátio da Cruz na PUC/SP para uma tarde com café e quitutes, música e boa conversa, o que intencionalmente colaborou para uma prática na qual se sentissem mais à vontade para trocarem experiências e se conhecerem. A atividade foi dividida em quatro momentos, descritos a seguir.

Em um primeiro momento, os alunos foram recebidos com música ambiente e quitutes. A seguir, todos foram convidados a se apresentarem na brincadeira "Meu nome multimodal". Cada um, ao dizer o nome em voz alta, tinha que fazer um gesto que o representasse. Em seguida, todos tinham que repetir, ao mesmo tempo, o nome e gesto apresentado. Após essa brincadeira, houve uma breve conversa que teve como pergunta disparadora: Como vocês se sentiram ao ter que dizer o nome e fazer os gestos?. Para participar da conversa, os alunos foram encorajados a translinguar - utilizando gestos, linguagem corporal, desenhos e sua própria língua, caso fosse necessário. Em seguida, apresentamos nossos objetivos com a atividade Bate-papo com Café e organizamos os alunos em pequenos grupos, compostos por alunos de nacionalidades diferentes. Cada grupo contou com pelo menos um educador.

Em um segundo momento, os alunos foram convidados a ouvir a música $O$ que é? O que é $?^{29}$ do Gonzaguinha. Após a música, nos pequenos grupos, tiveram que discutir o

\footnotetext{
${ }^{28}$ Esses alunos migrantes, de comunidades diversas, têm aula de português em locais distintos e foram convidados para essa atividade na PUC/SP, com o intuito de conhecerem outros migrantes na mesma situação, praticarem o que aprenderam de português até o momento e aprenderem mais sobre a língua portuguesa e o Brasil.

${ }^{29}$ Nos anos 70, com sua nítida repugnância ao governo militar, Gonzaguinha, por conta das letras de sua música, ficou muito conhecido na censura do Dops. Para gravar 18 músicas, Gonzaguinha submeteu 72 à
} 
que sentiram e pensaram enquanto ouviam a música. Depois da discussão, a letra da música foi entregue e, após a leitura, os alunos tiveram que discutir o conteúdo da letra da música, também nos pequenos grupos, com o auxílio, caso houvesse necessidade, dos educadores presentes. A seguir, um educador discorreu sobre o contexto da época de Gonzaguinha, compositor e cantor da música.

Em um terceiro momento, os alunos tiveram que marcar, na opinião deles, as palavras que consideravam mais marcantes na letra. A seguir, com lápis de cor tiveram que fazer uma representação da palavra ou das palavras escolhidas como marcantes. As palavras compuseram um varal junto com as representações dos demais grupos.

No momento final, com as palavras expostas em um varal, no pátio da Cruz, os alunos puderam livremente falar sobre o significado de cada palavra e rememorar situações vividas por eles ou familiares em seus próprios países de origem.

Nessa prática, ao lidar com a dramaticidade da superdiversidade, os alunos puderam construir as bases para viver o novo de forma desafiadora e potente. Ao se depararem com o outro, tiveram que lançar mão de múltiplos recursos para desenvolver novos "meios de falar" e recorreram ao seu repertório de vida e às suas histórias pessoais para participar das atividades propostas.

Acreditamos, na linha proposta, que a educação precisa ter como objetivo central o desenvolvimento de novos "meios de falar", como defendem Blommaert e Backus (2012, p. 3), por meio da proposição de eventos dramáticos, que se integrarão aos recursos que os alunos já carregam em seus repertórios e que poderão ser combinados individualmente a partir do patrimônio vivencial de cada sujeito. Só assim, os alunos ampliarão sua mobilidade no tempo e no espaço e, com isso, a possibilidade de vivenciar outros eventos dramáticos, dentro e fora da escola, que, por sua vez, podem gerar mais desenvolvimento.

Para isso, defendemos a ideia de que é preciso potencializar e ampliar o repertório espacial (OTSUJI; PENNYCOOK, 2010) de cada escola a partir da mobilização dos patrimônios vivenciais dos sujeitos envolvidos. Para tanto, as práticas translíngues merecem um lugar de destaque, uma vez que enfatizam a "ideia de zonas de contato e uma orientação mais aberta e dinâmica em relação às línguas, às linguagens e a outros recursos semióticos" (ROCHA; MACIEL, 2015, p. 425).

analise - 54 foram vetadas. Fazia dois ou três discos para poder gravar um. No entanto, sua criatividade e capacidade de manipulação da língua fez passar pela censura letras como "O que é? O que é”, dentre outras. 
Temos a expectativa e o profundo desejo de que nosso texto possa deflagrar uma experiência dramática e que vocês, leitores, possam incorporar, aos seus patrimônios vivenciais, novos recursos que se materializarão em novos "meios de falar" e, consequentemente, ampliem sua mobilidade e potencial de agência, como educadores, através do tempo e do espaço.

\section{REFERÊNCIAS}

ANDREWS, J.; YEE, W. C. Children's funds of knowledge and their real life activities: two minority ethnic children learning in out-of-school contexts in the UK. Educational Review, v. 58, n. 4, p. 435-449, 2006.

BLOMMAERT, J. Citizenship, language, and superdiversity: towards complexity. Journal of Language, Identity and Education, v. 12, n. 3, p. 193-196, 2013.

BLOMMAERT, J.; BACKUS, A. Superdiverse Repertoires and the Individual. Current Challenges for Educational Studies. In: SAINT-GEORGES, I. WEBER, J. J. (Eds.). Multilingualism and Multimodality. Sense, p. 11-32, 2013.

BLUNDEN, A. Notes on perejivanie. Ethical politics, 2014. Disponível em: $<$ https://www.ethicalpolitics.org/seminars/perezhivanie.htm> Acesso em: 4 jan. 2018.

BLUNDEN, A. Translating Perejivanie into English. Mind, Culture, and Activity, v.23, n.4, p. 274-283, 2016.

BUSCH, B. Expanding the notion of the linguistic repertoire: On the concept of Spracherleben: The lived experience of language. Applied Linguistics, v. 38, n. 3, p. 340$358,2015$.

BUSCH, B. The Linguistic Repertoire Revisited. Applied Linguistics, p. 1-22, 2012.

CANAGARAJAH, S. Translanguaging in the classroom: Emerging issues for research and pedagogy. Applied Linguistics Review, v. 2, p. 1-28, 2011.

CLARÀ, M. Vygotsky and Vasilyuk on perejivanie: two notions and one word. Mind, Culture, and Activity, v. 23, n. 4, p. 284-293, 2016.

DELARI, A.; BOBROVA PASSOS, I. V. Alguns sentidos da palavra "perejivánie" em L. S. Vigótski: notas para estudo futuro junto à psicologia russa. Mimeo. Umuarama/ Ivanovo, 2009.

ESTEBAN-GUITART, M. Funds of identity. New York, NY: Cambridge University Press, 2016. 
ESTEBAN-GUITART, M.; MOLL, L. C. Funds of Identity: A new concept based on the Funds of Knowledge approach. Culture and Psychology, v. 20, n. 1, p. 31-48, 2014.

GARCÍA, O. Bilingual education in the 21st century: A global perspective. Oxford: Wiley-Blackwell, 2009.

GARCÍA, O.; WEI, L. Translanguaging: language, bilingualism and education. New Yourk: Palgrave Macmillan, 2014.

GONZALEZ, N. The hybridity of funds of knowledge. In: GONZALEZ, N.; MOLL, L. C.; AMANTI, C. (Eds.), Funds of knowledge: Theorizing practices in households, communities and classrooms. New Jersey: Lawrence Erlbaum, p. 29-46, 2005.

GONZÁLEZ REY, F. Vygotsky's concept of perejivanie in the psychology of art and at the final moment of his work: Advancing his legacy. Mind, Culture, and Activity, v.23, n.4, p. 305-314, 2016.

HEATH, S. B. Ways with words: Language, life, and work in communities and classrooms. New York, NY: Cambridge University Press, 1996.

HEDGES, H.; CULLEN, J.; JORDAN, B. Early years curriculum: funds of knowledge as a conceptual framework for children's interests, Journal of Curriculum Studies, v.43, n.2, p. 185-205, 2011.

HOGG, L. Funds of knowledge: an investigation of coherence within the literature. Teaching and Teacher Education, v.27, p. 666-677, 2011.

LEWIS, O. The culture of poverty. Scientific American, v.215, n.4, p. 19-25, 1996.

LIBERALI, F. C.; FUGA, V. P. A importância do conceito de perejivanie na constituição de agentes transformadores. Estudos de Psicologia, Campinas, v.35, n.4, 2018.

MAHER. T. M. Do casulo ao movimento: a suspensão das certezas na educação bilíngüe e intercultural. In: CAVALCANTI, M. C.; BORTONI-RICARDO, S. M. (Orgs.). Transculturalidade, linguagem e educação. Campinas, SP: Mercado de Letras, p.67-94, 2007.

MOLL, L. C.; CAMMAROTA, J. Cultivating new funds of knowledge through research and practice. In: DUNSMORE, K.; FISHER, D. (Eds.). Bridging literacy home. Newark, DE: International Reading Association, 2010.

MOLL, L. C.; AMANTI, C.; Neff, D.; GONZÁLES, N. Funds of knowledge for teaching: using a qualitative approach to connect homes and classrooms. Theory into Practice, v.31, n.2, p. 132-141, 1992.

OTSUJI, E.; PENYCOOK, A. Metrolingualism: fixity, fluidity and language in flux. International Journal of Multilingualism, v.7, n.3, p. 240-254, 2010. Disponível em: 
<https://www.researchgate.net/publication/249025313_Metrolingualism_Fixity_Fluidity_ and_Language_in_Flux>. Acesso em: 24 mar. 2018.

PATTERSON, L.; BALDWIN, S. A different spin on parent involvement: exploring funds of knowledge within a systems perspective. In: GOODMAN, W. (Ed.). Living and teaching in an unjust world: new perspectives on multicultural education. Portsmouth, NH: Heinemann, p. 127-139, 2001.

POOLE, A.; JINGYI, H. Resituating funds of identity within contemporary interpretations of perejivanie. Mind,Culture, and Activity, v.25, n.2, p. 125-137, 2018.

ROCHA, C. H.; MACIEL, R. Ensino de língua estrangeira como prática translíngue: articulações com teorizações bakhtinianas. D.E.L.T.A., v. 31, n. 2, p. 411-445, 2015.

RYAN, W. Blame the victim. NY: Vintage Books, 1972.

RYMES, B. Communicative Repertoire. In: STREET, B.; LEUNG, C. (Orgs.). Routledge Companion to English Language Studies. New York/London: Routledge, 2014.

VERTOVEC, S. Super-diversity and its implications. Ethnic and Racial Studies, v.30, n.6, p. 1024-1054, 2007.

VAN DER VEER, R.; VALSINER, J. The Vygotsky reader. Oxford, UK: Blackwell, 1994.

VINHA, M. P.; WELCMAN, M. Quarta aula: a questão do meio na pedologia, Lev Semionovich Vigotski. Psicol. USP [online], v21, n.4, p.681-701, 2010.

VYGOTSKY, L. S. The psychology of the actor's creative work. In: RIEBER, R. W. (Ed.). The collected works of L. S. Vygotsky, vol. 6, New York: Plenum, 1999.

VYGOTSKY, L. S. [1934]. The problem of the environment. In: VAN DER VEER, R.; VALSINER, J. (Eds.). The Vygotsky reader. Oxford: Blackwell, 1994.

WOLF, E. Peasants. Englewood Cliffs, NJ: Prentice-Hall, 1966.

Recebido em: 31 out. 2019. Aceito em: 03 jan. 2020. 